\title{
Validation of Microbiological Testing of Cellular Medicinal Products Containing Antibiotics
}

\author{
Ramin Lotfia, ${ }^{a}$ Markus Thomas Rojewski ${ }^{a, b}$ Philip H. Zeplin ${ }^{c}$ Wolfgang Funk ${ }^{d}$ \\ Oliver Pullige Ulrich Nöth ${ }^{\mathrm{f} g}$ Hubert Schrezenmeier ${ }^{\mathrm{a}, \mathrm{b}}$ \\ ${ }^{a}$ Institut für Transfusionsmedizin, Universität Ulm, Ulm, Germany; ${ }^{b}$ Institute for Clinical Transfusion Medicine and

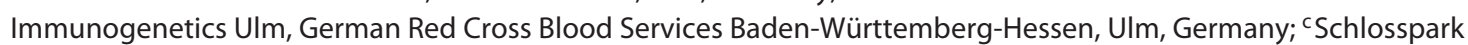

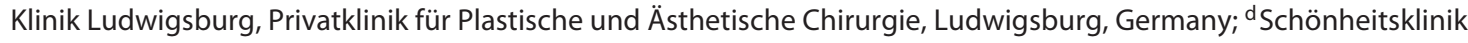 \\ Dr. Funk, München, Germany; ${ }^{e}$ Department Tissue Engineering and Regenerative Medicine (TERM), University \\ Hospital Würzburg, Würzburg, Germany; ${ }^{\mathrm{f} E v a n g e l i s c h e s ~ W a l d k r a n k e n h a u s ~ S p a n d a u, ~ K l i n i k ~ f u ̈ r ~ O r t h o p a ̈ d i e ~}$ \\ und Unfallchirurgie, Berlin, Germany; ${ }^{9}$ Department of Orthopaedic Surgery, König-Ludwig-Haus, Center for \\ Musculoskeletal Research, Julius-Maximilians-University, Würzburg, Germany
}

\author{
Keywords \\ Advanced therapy medicinal product · Mesenchymal \\ stromal/stem cells $\cdot$ Sterility $\cdot$ Microbial contamination . \\ Antibiotics
}

\begin{abstract}
Background: The risk of microbial contamination of cellular products can be reduced when cultured in the presence of antibiotics. This however, may impact the sensitivity of microbiological tests. Given that the addition of antibiotics to cell/tissue products does not guarantee sterility but may just reduce the proliferation rate of microorganisms, microbiological testing of medicinal products remains obligatory. Thus, an appropriate method to test for microbial contamination of antibiotic-containing products has to be validated. Objectives: In the context of microbiological testing of a cellular advance therapy medicinal product, the method was validated and approved by German competent authorities for four different matrices with three matrices containing antibiotics. The paper shall provide help for establishing test methods for other investigational medicinal products which contain antibiotics. Methods: Matrices were spiked individually with Staphylococcus aureus, Bacillus subtilis, Pseudomonas aeruginosa, Streptococcus pyogenes, Escherichia coli, Clostridium sporogenes, Propionibacterium acnes, Candida albi-
\end{abstract}

cans, and Aspergillus brasiliensis. Samples were pretreated with penicillinase for $1 \mathrm{~h}$ before inoculation and incubation in BacT/ALERT iFA Plus and iFN Plus culture bottles using 3D BacT/ALERT automates. Microorganisms within positive BacT/ALERT bottles were specified. The procedure was performed in two different laboratories to prove robustness of test. Results: All nine tested microorganisms were detected within 14 days of incubation in accordance with requirements of the European Pharmacopoiea in terms of sensitivity, specificity and robustness of the test. Penicillin and streptomycin did not have any influence on specifications defined within the investigational medicinal product dossier. Conclusions: Culturing cellular products in the presence of antibiotics can serve as an effective method to reduce contamination risk but only if the chosen antibiotics neither have any influence on specifications of the investigational medicinal product nor interfere with microbiological tests. Consequently, cells and tissues primarily contaminated with microorganisms, like placenta, may be considered as a source of cellular therapeutics when cultured for a sufficient time with antibiotics and tested with a validated method. The choice of microorganisms for the validation of the microbiological test should always consider all conceivable scenarios and should not be reduced to minimal criteria defined in European Pharmacopoiea, wrongfully believing to thus save time and effort.

(c) 2019 S. Karger AG, Basel 


\section{Introduction}

The risk of microbial contamination of tissue and cellular products can be reduced significantly when cultured in the presence of antibiotics and antimycotics. This, however, may impact the sensitivity of microbiological tests performed for the detection of microorganisms in such products. Given that the addition of antibiotics to cell/tissue products does not guarantee sterility but may just reduce the proliferation rate of microorganisms, a validated microbiological testing which excludes such possibility of false-negative results remains obligatory.

In Europe, sterility tests are performed either by membrane filtration method or by inoculation method according to European Pharmacopoeia chapter 2.6.1. (an overview is given in Fig. 1), but due to their nature, some cellular products cannot be tested for sterility as required in this chapter. For instance, some microbiological contaminants are located on the surface of the cells or within the cells and thus cannot be detected in the surrounding culture or transport media. In these cases, a cell suspension (not just the culturing media) has to be tested, but such a sample is not suitable for membrane filtration method which has to be performed with a maximal membrane pore size of $0.45 \mu \mathrm{m}$ (European Pharmacopoeia chapter 2.6.1.). Furthermore, medicinal products consisting of suspensions with higher cell concentrations do not allow a reliable assessment of changes in turbidity, as required for the inoculation method. Sample size may be another issue limiting the implementation of European Pharmacopoiea 2.6.1., especially with products from individual donors such as hematopoietic stem cells or the limited capacity of the manufacturing methodology leading to a limited size of available sample.

Since sterility testing of cellular products is not possible, these products have to be tested according to chapter 2.6.27 for microbial contamination by a validated method (Fig. 1).

Minimal qualitative and quantitative requirements for microorganisms which have to be considered in the validation of the microbiological test method are listed in European Pharmacopoeia, but depending on the source of cells/tissue used for the medicinal product a thorough risk analysis of the potential and/or relevant contaminating microorganisms has to be performed, and the spectrum of tested microorganisms has to be adapted.

Currently, mesenchymal stromal cells (MSCs) are applied as an advanced therapy medicinal product (ATMP) in many clinical trials (www.clinicaltrials.gov). MSCs may be isolated and expanded from different tissues [1] such as bone marrow or adipose tissue [2]. Subcutaneous fat is an easily accessible tissue, but it has a higher risk of contamination with organisms residing in deeper sites of the skin which are not always sufficiently reached by dis- infectants used for skin decontamination before liposuction. While a minimal bacterial contamination during liposuction procedures may not be relevant for a healthy individual who is not immunocompromised, this may influence the quality of fat tissue ex vivo, where microorganisms may grow much more easily without the immune surveillance which is present in vivo.

The higher contamination rate of adipose tissue obtained by liposuction may require treatment of fat tissue with antibiotics before isolating adipocyte-derived MSCs (ASCs) as well as culturing such ASCs in media supplemented with antibiotics [3]. In the context of a European multicenter clinical trial (ADIPOA2, EudraCT 2015002125-19), our institution produces autologous ASCs within 14 days ( \pm 1 day) following lipoaspiration. At the beginning of the project, we faced a contamination rate of lipoaspirates of about $50 \%$ (range: $37-75 \%$ ) with fat tissue obtained from four different clinical centers. Thus, our production site has now implemented antibiotic treatment of cells for the first 8 days ( \pm 1 day) of culturing.

In-process microbiological testing had to be performed on the starting material (i.e., fat tissue), two interim products, and the final cellular product. Therefore, the microbiological test method had to be validated for four individual matrices, due to their qualitative and quantitative differences. Table 1 demonstrates the characteristics of each matrix. The procedure and the validated microbiological testing have been approved by German competent authorities. The paper shall give insight into the validation process and provide help for establishing a similar procedure and testing method for further cell- or tissue-based ATMPs.

\section{Materials and Methods}

For the validation of the microbiological test method lipoaspirates were obtained from healthy donors undergoing liposuction for cosmetic reasons, with written informed consent to donate drawn fat tissue for indicated research purpose. ASCs were produced within 14 days ( \pm 1 day) out of about $60-100 \mathrm{~g}$ of fat tissue. An overview on the production steps of the investigational medicinal product is given in Figure 2.

Flow cytometry of ASCs was performed as previously described $[4,5]$. In brief, $1 \times 10^{6}$ to $4 \times 10^{6}$ ASCs were washed in DPBS (Lon$\mathrm{za}$, Switzerland) and resuspended in $100 \mu \mathrm{L}$ of DPBS. Cells were stained with a combination of either (1) IgG-FITC $(20 \mu \mathrm{L}$, clone $\mathrm{X} 40), \operatorname{IgG}-\mathrm{PE}(20 \mu \mathrm{L}$, clone X40) and IgG-PerCP $(20 \mu \mathrm{L}$, clone $\mathrm{X} 40)$, (2) CD90-FITC $(1 \mu \mathrm{L}$, clone 5E10), CD34-PE $(20 \mu \mathrm{L}$, clone $8 \mathrm{G} 12)$, and CD14-PerCP (20 $\mu \mathrm{L}$, clone MøP9), (3) CD73-FITC (10 $\mu \mathrm{L}$, clone AD2), CD31-PE (20 $\mu \mathrm{L}$, clone WM59), and CD45-PerCP (20 $\mu \mathrm{L}$, clone $2 \mathrm{D} 1)$, or (4) CD105-FITC (10 $\mu \mathrm{L}$, clone SN6) and CD13-PE $(20 \mu \mathrm{L}$, clone WM15), respectively. Antibodies were purchased from BD Biosciences (Germany), except for CD105 (Bio-Rad AbD Serotec GmbH, Germany). After 15-20 min staining at ambient temperature, cells were washed in DPBS and the fluorescence intensity of 50,000 cells was acquired using a FACScan with CellQuest 3.3 software (BD Biosciences). 


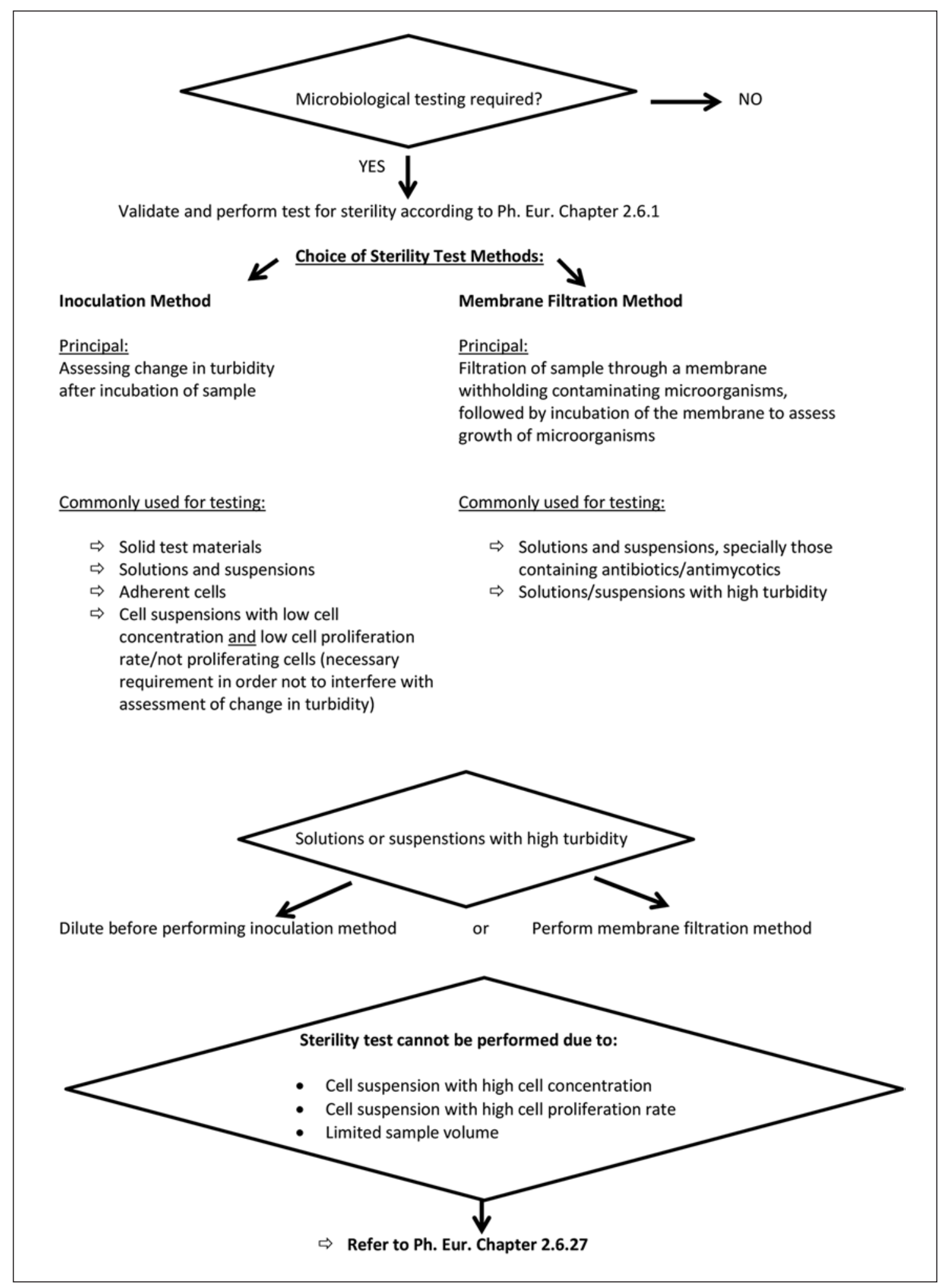

Fig. 1. Overview on tests for microbial contamination based on European Pharmacopoiea chapters 1.6.2 and 1.6.27.

Each of the four matrices listed in Table 1 was spiked with microorganisms listed in Table 2 and inoculated into BacT/ALERT culture bottles containing a resin to bind and neutralize the remaining antibiotics $[6,7]$. In order to inactivate penicillin, all ma- trices containing antibiotics (i.e., matrices I-III; see Table 1) were preincubated with $100 \mu \mathrm{g}$ penicillinase (Becton Dickinson, Germany; Ref. No. 215331) per mL matrix for $1 \mathrm{~h}$ at room temperature, before inoculation into BacT/ALERT culture bottles. BacT/ 


\begin{tabular}{|c|c|c|}
\hline & $\begin{array}{l}\text { Time } \\
\text { point }\end{array}$ & Description \\
\hline & Day 0 & $\begin{array}{l}\text { Liposuction with subsequent } \\
\text { incubation of lipoaspirate in: } \\
100 \mathrm{U} \text { penicillin and } 100 \mu \mathrm{g} \text { streptomycin per ml culturing media }\end{array}$ \\
\hline & Day 0 & $\begin{array}{l}\text { Fermentation of lipoaspirate with collagenase in order to obtain } \\
\text { stromal vascular fraction (SVF) with subsequent culturing of SVF in: } \\
\text { Alpha-MEM supplemented with } 5 \% \text { human platelet lysate plus } 1 \mathrm{IU} \text { Heparin/ml, } \\
100 \mathrm{U} \text { penicillin and } 100 \mu \mathrm{g} \text { streptomycin per } \mathrm{ml} \text { culturing media }\end{array}$ \\
\hline & Day 1 & $\begin{array}{l}\text { Media exchange in order to remove non-adherent cells and culturing in: } \\
\text { Alpha-MEM supplemented with } 5 \% \text { human platelet lysate plus } 1 \mathrm{IU} \text { Heparin/ml, } \\
100 \mathrm{U} \text { penicillin and } 100 \mu \mathrm{g} \text { streptomycin per } \mathrm{ml} \text { culturing media }\end{array}$ \\
\hline & Day $4 \pm 1$ & $\begin{array}{l}\text { Media exchange and culturing in: } \\
\text { Alpha-MEM supplemented with } 5 \% \text { human platelet lysate plus } 1 \mathrm{IU} \text { Heparin/ml, } \\
100 \mathrm{U} \text { penicillin and } 100 \mathrm{\mu g} \text { streptomycin per ml culturing media }\end{array}$ \\
\hline & Day $6 \pm 1$ & $\begin{array}{l}\text { Media exchange and culturing in: } \\
\text { Alpha-MEM supplemented with } 5 \% \text { human platelet lysate plus } 1 \mathrm{IU} \text { Heparin/ml, } \\
100 \mathrm{U} \text { penicillin and } 100 \mu \mathrm{g} \text { streptomycin per } \mathrm{ml} \text { culturing media }\end{array}$ \\
\hline & Day $8 \pm 1$ & $\begin{array}{l}\text { Harvest/Passage of adipocyte derived mesenchymal stromal cells (ASCS) } \\
\text { and culturing in: } \\
\text { Alpha-MEM supplemented with } 5 \% \text { human platelet lysate plus } 1 \text { IU Heparin } / \mathrm{ml}, \\
\text { (no antibiotics) }\end{array}$ \\
\hline & Day $11 \pm 1$ & $\begin{array}{l}\text { Media exchange and culturing in: } \\
\text { Alpha-MEM supplemented with } 5 \% \text { human platelet lysate plus } 1 \mathrm{IU} \text { Heparin/ml, } \\
\text { (no antibiotics) }\end{array}$ \\
\hline & Day $13 \pm 1$ & $\begin{array}{l}\text { Media exchange and culturing in: } \\
\text { Alpha-MEM supplemented with } 5 \% \text { human platelet lysate plus } 1 \mathrm{IU} \text { Heparin/ml, } \\
\text { (no antibiotics) }\end{array}$ \\
\hline $\begin{array}{l}\text { Fig. 2. Overview on the production steps of } \\
\text { ASCs. }\end{array}$ & Day $14 \pm 1$ & $\begin{array}{l}\text { Harvest of end-product and resuspension of ASCs in } \\
4,5 \% \text { Albumin in } \mathrm{NaCl} \text { with } 0,5 \% \text { glucose } \\
\text { (no antibiotics) }\end{array}$ \\
\hline
\end{tabular}

ALERT iFA Plus and iFN Plus (bioMérieux, Germany) were used for aerobic and anaerobic microorganisms, respectively. To assess intraassay variability, each microorganism was tested as duplicate within every setting. The matrix by itself served as negative control, while isotonic $\mathrm{NaCl}$ solution spiked with the microorganism of interest was used as positive control. Initially, $30 \mathrm{CFU}$ was inoculated in each matrix, and the CFU was raised stepwise to 60 and 90 , whenever the detection of the inoculated microorganism was not successful after 14 days of incubation. All microorganisms were purchased as BioBalls from bioMérieux and reconstituted according to the manufacturer's guidelines.

For each positive finding, the microorganism responsible for the positive BacT/ALERT result was verified by microbiological characterization, in order to confirm the specificity of positive results.
In order to validate the microbiological detection method in two different laboratories, the whole procedure was performed twice: after inoculation with the indicated microorganisms, one set of BacT/ALERT culture bottles remained in the Institute for Transfusion Medicine and Immunogenetics Ulm (IKT Ulm) and were incubated in the quality control laboratories of IKT Ulm, while the other set of inoculated bottle were transferred within 3 $\mathrm{h}$ (at ambient temperature) to the quality control laboratories of the Institute of Transfusion Medicine and Immunology in Mannheim. In both institutes, BacT/ALERT 3D automates [8] (bioMérieux) were used for incubation of culture bottles at temperatures optimal for the growth of inoculated microorganisms (Table 2). For specification of microorganisms responsible for positive BacT/ALERT results the bottles were sent to the institute 
Table 1. Specifications of matrices for which the microbiological test was validated

\begin{tabular}{|c|c|c|c|c|c|}
\hline & Matrix & $\begin{array}{l}\text { Pen/ } \\
\text { Strep }\end{array}$ & $\begin{array}{l}\text { Inoculation } \\
\text { volume, } \mathrm{mL}^{1}\end{array}$ & Cell concentration & Solution used for cell suspension \\
\hline I & Lipoaspirate & + & 1 & $\mathrm{~N} / \mathrm{A}$ & $\mathrm{N} / \mathrm{A}$ \\
\hline II & Stromal vascular fraction & + & 5.7 & $17.88 \times 10^{3}$ cells $/ \mathrm{mL}$ & $a-M E M+5 \%$ PL + 1 IU heparin $/ m L$ \\
\hline III & ASCs (day $8 \pm 1$ ) & + & 5.7 & $8.94 \times 10^{3} \mathrm{ASCs} / \mathrm{mL}$ & $a-M E M+5 \% \mathrm{PL}+1 \mathrm{IU}$ heparin $/ \mathrm{mL}$ \\
\hline IV & End product (day $14 \pm 1$ ) & - & 5 & $2 \times 10^{6} \mathrm{ASCs} / \mathrm{mL}$ & $4.5 \%$ albumin in $\mathrm{NaCl}$ with $0.5 \%$ glucose \\
\hline
\end{tabular}

ASCs, adipocyte-derived mesenchymal stromal cells; $\alpha$-MEM, alpha modification of minimal essential medium; PL, platelet lysate; Pen/Strep, penicillin/streptomycin at final concentration of $100 \mathrm{U} / \mathrm{mL}$ and $\mu \mathrm{g} / \mathrm{mL}$, respectively. ${ }^{1}$ According to European Pharmacopoiea the inoculation volume was at least $1 \%$ of the matrix which had to be tested.

for microbiology of the University of Ulm or the University of Mannheim, respectively.

Statistical analysis was performed using GraphPad Prism 7.01 Software for Windows. Data were compared using the MannWhitney U test. Differences were considered significant at $p<0.05$.

\section{Results}

Flow cytometric data on characteristic surface markers comparing antibiotic-treated ASCs to ASCs without antibiotic treatment confirmed that the addition of penicillin and streptomycin to the culturing media at the indicated dose and duration did not have any significant influence on the cells in terms of cell identity. Regardless of their treatment with antibiotics, ASCs of the end product were negative for hematopoietic markers CD34, CD14, CD 45, and CD 31 and positive for CD 73, CD 90, CD 105, and CD13 (Fig. 3).

Likewise, the proliferative behavior of antibiotic-treated cells did not show any significant changes which would influence the target cell number at the time of harvesting of the end product. Even though the number of cells within the stromal vascular fraction obtained from digested lipoaspirates was smaller when lipoaspirates were pretreated with antibiotics, the following data on viability and proliferation were comparable to those without antibiotic exposure. Specifically, both groups showed similar population doubling times, cell density, and harvested cell number at the time of first harvest (day $8[ \pm 1]$ ) and at the time of harvesting the end product (Table 3 ).

Table 4 provides detailed information on the results from both validation runs for microbiological testing of the indicated microorganisms. All tested microorganisms that spiked at 30-90 CFU could be detected within 4 days of incubation at indicated temperatures, except for Propioni acnes, which is known to belong to a slow proliferating microorganism. An incubation period between 7 and 14 days at $35^{\circ} \mathrm{C}$ was necessary to detect $P$. acnes.

For matrix IV containing no antibiotics, the sensitivity of the test for all spiked microorganisms was at $30 \mathrm{CFU}$
Table 2. List of microorganisms used for validation of the microbiological test method

\begin{tabular}{ll}
\hline Species & Incubation temperature, ${ }^{\circ} \mathrm{C}$ \\
\hline Aaerobic bacteria & $30-32$ \\
$\quad$ Staphylococcus aureus & \\
$\quad$ Bacillus subtilis \\
$\quad$ Pseudomonas aeruginosa \\
$\quad$ Streptococcus pyogenes \\
$\quad \begin{array}{l}\text { Escherichia coli } \\
\text { Anaerobic bacteria }\end{array}$ \\
$\quad$ Clostridium sporogenes \\
$\quad$ Propionibacterium acnes \\
Fungi \\
$\quad$ Candida albicans \\
$\quad$ Aspergillus brasiliensis
\end{tabular}

(Table 4). With regard to antibiotic-containing matrices (i.e., matrices I-III), the method showed a sensitivity of $30 \mathrm{CFU}$ for six out of the nine tested microorganisms. The detection threshold for Bacillus subtilis and Pseudomonas aeruginosa was at $60 \mathrm{CFU}$ while Escherichia coli could be detected with a sensitivity of 90 CFU.

The robustness of the test method could be confirmed by obtaining comparable results from two independent validation runs in two different laboratories (Table 4). The specificity of positive results was confirmed by verification of the microorganism responsible for the positive BacT/ALERT finding (Table 4).

\section{Discussion/Conclusion}

Even though the present work focused on the validation strategy for microbiological testing of antibiotic-exposed ASCs, the entire cell processing procedure and the final aim of the study should be kept in mind, which is the production of an ATMP which shall not be influenced by modifications in the production process. Taking into account the possible impact of applied antibiotics on the 
Table 3. Treatment with penicillin and streptomycin does not influence proliferative properties of ASCs: list of key parameters for ASCs expanded in the absence or presence of penicillin and streptomycin

\begin{tabular}{|c|c|c|c|c|}
\hline Parameter & $\begin{array}{l}\text { Expansion in: } \\
\text { a-MEM } 5 \% \text { platelet lysate } \\
\text { without antibiotics }\end{array}$ & $\begin{array}{l}\text { Expansion in: } \\
\text { a-MEM } 5 \% \text { platelet lysate } \\
100 \mathrm{IU} / \mathrm{mL} \text { penicillin }+100 \mu \mathrm{g} / \mathrm{mL} \\
\text { streptomycin }\end{array}$ & $\begin{array}{l}\text { Specification } \\
\text { according to } \\
\text { IMPD of ADIPOA2 }\end{array}$ & $\begin{array}{l}p \\
\text { value }\end{array}$ \\
\hline SVF cells $/ \mathrm{mL}$ lipoaspirate & $5.78 \times 10^{5}\left(3.78 \times 10^{5}-8.52 \times 10^{5}\right)$ & $1.43 \times 10^{5}\left(1.08 \times 10^{5}-1.85 \times 10^{5}\right)$ & not specified & 0.03 \\
\hline Viability of cells of the SVF & $92.94(89.15-95.97)$ & $73.91(71.31-76.49)$ & $\geq 70 \%$ & 0.03 \\
\hline CFU-F $/ 10^{6}$ cells of the SVF & $10.09 \times 10^{4}\left(6.56 \times 10^{4}-29.31 \times 10^{4}\right)$ & $9.72 \times 10^{4}\left(9.44 \times 10^{4}-10.50 \times 10^{4}\right)$ & variable & 0.69 \\
\hline Harvest density at day $8( \pm 1)$ & $5.35 \times 10^{4}\left(3.62 \times 10^{4}-6.13 \times 10^{4}\right)$ & $5.31 \times 10^{4}\left(4.09 \times 10^{4}-6.68 \times 10^{4}\right)$ & $\mathrm{NA}$ & 0.86 \\
\hline Viability at day $8( \pm 1), \%$ & $99.70(99.30-100.00)$ & $100.00(100.00-100.00)$ & $\geq 80$ & 0.43 \\
\hline CFU-F/ $10^{6}$ at day $8( \pm 1)$ & $25.58 \times 10^{4}\left(24.25 \times 10^{4}-32.92 \times 10^{4}\right)$ & $4.43 \times 10^{4}\left(2.36 \times 10^{4}-27.67 \times 10^{4}\right)$ & variable & 0.40 \\
\hline Harvested ASC at day 8 per SVF & $13.36(9.04-15.33)$ & $13.27(10.22-16.71)$ & not specified & 0.86 \\
\hline Harvest density of end product & $6.10 \times 10^{4}\left(5.48 \times 10^{4}-6.67 \times 10^{4}\right)$ & $4.87 \times 10^{4}\left(3.97 \times 10^{4}-6.56 \times 10^{4}\right)$ & not specified & 0.40 \\
\hline Viability, of end product, \% & $98.91(95.40-100.00)$ & $91.82(91.80-98.67)$ & $\geq 90$ & 0.23 \\
\hline CFU-F $/ 10^{6}$ of end product & $31.77 \times 10^{4}\left(20.92 \times 10^{4}-63.75 \times 10^{4}\right)$ & $50.00 \times 10^{4}\left(36.00 \times 10^{4}-85.25 \times 10^{4}\right)$ & variable & 0.63 \\
\hline Doubling time of end product, days & $34.36(29.69-37.96)$ & $31.34(28.61-33.41)$ & $>15.00$ & 0.23 \\
\hline End product cells/ASC at day 8 & $30.50(27.42-33.32)$ & $24.17(19.83-32.74)$ & not specified & 0.40 \\
\hline Total harvest & $143.10 \times 10^{6}\left(81.80 \times 10^{6}-169.64 \times 10^{6}\right)$ & $170.00 \times 10^{6}\left(103.95 \times 10^{6}-202.50 \times 10^{6}\right)$ & $\begin{array}{l}\geq 20 \times 10^{6}(\text { high dose }) \\
\geq 12 \times 10^{6}(\text { low dose })\end{array}$ & 0.86 \\
\hline
\end{tabular}

Values indicate median (range). $a$-MEM, alpha modification of minimal essential medium; IMPD, Investigational Medicinal Product Dossier; ADIPOA2, clinical trial: A phase $2 \mathrm{~b}$ Study Evaluating the Efficacy of a Single Injection Autologous Adipose Derived Mesenchymal Stromal Cells in Patients with Knee Osteoarthritis (EudraCT No. 2015-002125-19); SVF, stromal vascular fraction (i.e., obtained cells following digestion of lipoaspirate); CFU-F, colony-forming unit fibroblasts.

Fig. 3. Treatment with penicillin and streptomycin does not influence characteristic cell surface markers of ASCs. Flow cytometry analysis of the ASC final product expanded in medium with or without the antibiotics penicillin and streptomycin. Mean values for the percentage of cells expressing the indicated antigens are shown. Bars indicate standard deviation. n.s., not significant (i.e., $p>0.05$ ). Pen/Strep - indicates cells grown in the absence of penicillin/ streptomycin. Pen/Strep + indicates cells grown in the presence of $100 \mathrm{IU}$ penicillin/ $\mathrm{mL}$ and $100 \mu \mathrm{g}$ streptomycin/mL, until day $8( \pm 1)$.

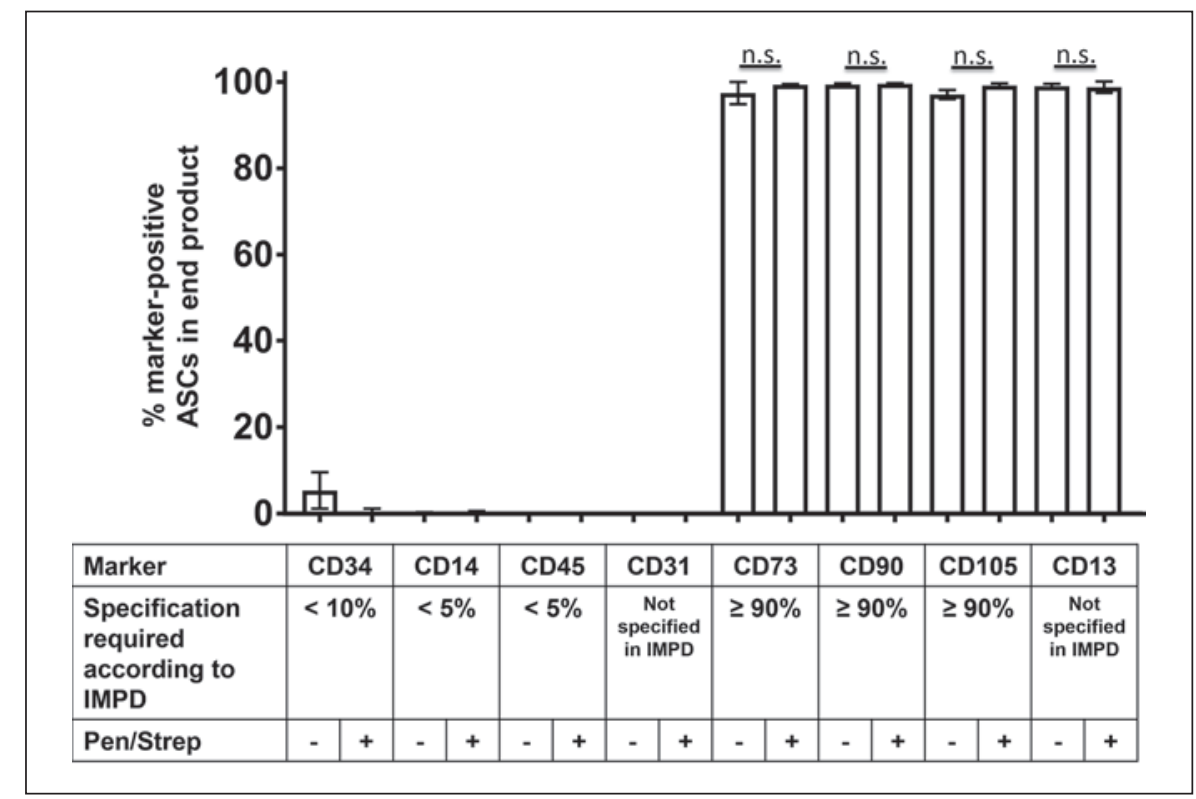

biology of cellular products, specifically on ASCs [9], we performed tests confirming the identity of ASCs by measuring their surface markers on the basis of the statement of the International Federation for Adipose Therapeutics and Science (IFATS) and the International Society for Cellular Therapy (ISCT) [10] (Fig. 1) and in accordance with requirements defined in the Investigational Medicinal Product Dossier (IMPD). Based on the observation of high interindividual differences in the proliferation rate of ASCs, the proliferative behavior of antibiotic-exposed ASCs was assessed by focusing rather on the question of whether the cell number sufficient for the aimed therapeutic dose is achieved, but not asking whether the proliferation rate of antibiotic-exposed ASCs differs statisti- cally significantly from that of ASCs not treated with antibiotics. This rationale shall provide an example for cases where a mere statistical analysis may not be helpful for the evaluation of relevant implications of methodological changes.

Comparing the results from matrix IV with those from matrices I-III, the presence of antibiotics within matrices I-III seems to impact the sensitivity of detection of E. coli, B. subtilis, and P. aeruginosa, which had to be spiked with higher than $30 \mathrm{CFU}$. However, the sensitivity was within the required range of $10-100 \mathrm{CFU}$ and thus in agreement with European Pharmacopoiea.

Based on our results, the treatment of samples with penicillinase in combination with the use of culture bot- 
Table 4. Detailed results from both validation runs for microbiological testing of the indicated microorganisms

\begin{tabular}{|c|c|c|c|c|c|c|c|c|c|c|c|c|c|c|c|c|c|}
\hline \multirow{3}{*}{$\begin{array}{l}\text { Spiked micro- } \\
\text { organism }\end{array}$} & \multirow{3}{*}{$\begin{array}{l}\text { Specified } \\
\text { microorganism after } \\
\text { positive } \\
\text { BacT/ALERT } \\
\text { result identical } \\
\text { with spiked microor- } \\
\text { ganism }\end{array}$} & \multicolumn{4}{|c|}{ Matrix I } & \multicolumn{4}{|c|}{ Matrix II } & \multicolumn{4}{|c|}{ Matrix III } & \multicolumn{4}{|c|}{ Matrix IV } \\
\hline & & \multicolumn{2}{|l|}{ Run 1} & \multicolumn{2}{|l|}{ Run 2} & \multicolumn{2}{|l|}{ Run 1} & \multicolumn{2}{|l|}{ Run 2} & \multicolumn{2}{|l|}{ Run 1} & \multicolumn{2}{|l|}{ Run 2} & \multicolumn{2}{|l|}{ Run 1} & \multicolumn{2}{|l|}{ Run 2} \\
\hline & & $\begin{array}{l}\text { time } \\
\text { to de- } \\
\text { tect, } \\
\text { days }\end{array}$ & $\mathrm{CFU}^{1}$ & $\begin{array}{l}\text { time } \\
\text { to de- } \\
\text { tect, } \\
\text { days }\end{array}$ & $\mathrm{CFU}^{1}$ & $\begin{array}{l}\text { time } \\
\text { to de- } \\
\text { tect, } \\
\text { days }\end{array}$ & $\mathrm{CFU}^{1}$ & $\begin{array}{l}\text { time } \\
\text { to de- } \\
\text { tect, } \\
\text { days }\end{array}$ & $\mathrm{CFU}^{1}$ & $\begin{array}{l}\text { time } \\
\text { to de- } \\
\text { tect, } \\
\text { days }\end{array}$ & $\mathrm{CFU}^{1}$ & $\begin{array}{l}\text { time } \\
\text { to de- } \\
\text { tect, } \\
\text { days }\end{array}$ & $\mathrm{CFU}^{1}$ & $\begin{array}{l}\text { time } \\
\text { to de- } \\
\text { tect, } \\
\text { days }\end{array}$ & $\mathrm{CFU}^{1}$ & $\begin{array}{l}\text { time } \\
\text { to de- } \\
\text { tect, } \\
\text { days }\end{array}$ & $\mathrm{CFU}^{1}$ \\
\hline S.aureus & yes & 1.03 & 30 & 0.99 & 30 & 1.01 & 30 & 1.41 & 30 & 0.86 & 30 & 1.05 & 30 & 0.84 & 30 & 0.89 & 30 \\
\hline B. subtilis & yes & 0.84 & 30 & 0.73 & 60 & 3.27 & 90 & 2.07 & 30 & 0.78 & 30 & 0.71 & 60 & 0.77 & 30 & 0.83 & 30 \\
\hline B. subtilis & yes & 0.82 & 30 & 0.73 & 60 & 3.19 & 90 & 1.92 & 30 & 0.80 & 30 & 0.71 & 60 & 0.75 & 30 & 0.80 & 30 \\
\hline P. aeruginosa & yes & 0.99 & 30 & 0.83 & 60 & 0.93 & 30 & 1.00 & 60 & 0.91 & 30 & 0.81 & 60 & 0.90 & 30 & 0.92 & 30 \\
\hline P. aeruginosa & yes & 0.94 & 30 & 0.85 & 60 & 0.96 & 30 & 1.01 & 60 & 0.92 & 30 & 0.82 & 60 & 0.89 & 30 & 0.88 & 30 \\
\hline A. brasiliensis & yes & 2.61 & 30 & 2.34 & 30 & 2.93 & 30 & 2.62 & 30 & 2.59 & 30 & 2.45 & 30 & 1.87 & 30 & 1.93 & 30 \\
\hline A. brasiliensis & yes & 2.00 & 30 & 2.20 & 30 & 2.57 & 30 & 2.23 & 30 & 2.54 & 30 & 2.70 & 30 & 2.00 & 30 & 2.20 & 30 \\
\hline C. albicans & yes & 1.86 & 30 & 1.32 & 30 & 2.13 & 30 & 1.62 & 30 & 1.96 & 30 & 1.35 & 30 & 1.13 & 30 & 1.18 & 30 \\
\hline C. albicans & yes & 1.61 & 30 & 1.33 & 30 & 2.15 & 30 & 1.91 & 30 & 1.74 & 30 & 1.36 & 30 & 1.12 & 30 & 1.16 & 30 \\
\hline S. pyogenes & yes & 0.74 & 30 & 0.81 & 30 & 0.80 & 30 & 0.75 & 30 & 0.73 & 30 & 0.78 & 30 & 0.74 & 30 & 0.78 & 30 \\
\hline S. pyogenes & yes & 0.73 & 30 & 0.83 & 30 & 0.78 & 30 & 0.75 & 30 & 0.73 & 30 & 0.82 & 30 & 0.77 & 30 & 0.76 & 30 \\
\hline E. coli & yes & 0.71 & 90 & 0.73 & 30 & 0.73 & 60 & 0.72 & 60 & 0.63 & 30 & 0.57 & 60 & 0.64 & 30 & 0.64 & 30 \\
\hline E. coli & yes & 0.74 & 90 & 0.74 & 30 & 0.81 & 60 & 0.70 & 60 & 0.62 & 30 & 0.54 & 60 & 0.66 & 30 & 0.64 & 30 \\
\hline P. acnes & yes & 12.93 & 30 & 9.91 & 30 & 10.35 & 30 & 8.97 & 30 & 10.29 & 30 & 8.26 & 30 & 7.82 & 30 & 6.95 & 30 \\
\hline P. acnes & yes & 13.49 & 30 & 10.05 & 30 & 9.84 & 30 & 8.54 & 30 & 9.92 & 30 & 8.51 & 30 & 7.96 & 30 & 6.56 & 30 \\
\hline C. sporogenes & yes & 0.86 & 30 & 1.43 & 30 & 0.87 & 30 & 0.94 & 30 & 1.06 & 30 & 1.08 & 30 & 0.79 & 30 & 1.31 & 30 \\
\hline C. sporogenes & yes & 0.85 & 30 & 1.20 & 30 & 1.05 & 30 & 0.97 & 30 & 0.91 & 30 & 0.99 & 30 & 0.83 & 30 & 1.26 & 30 \\
\hline
\end{tabular}

${ }^{1}$ Amount of $\mathrm{CFU}$ with which the microorganisms were spiked.

tles providing an antibiotic-adsorbing resin allows reliable microbiological testing of penicillin/streptomycincontaining cellular matrices.

With regard to the here presented data, patients treated with antibiotics may also be considered for inclusion in studies applying autologous cells or tissues. Furthermore, cells and tissues primarily contaminated with microorganisms, like decidual blood or placenta, may possibly serve as a source of cellular therapeutics, if the antibiotics:

(a) have been applied for a sufficient time,

(b) have been applied at adequate concentrations,

(c) do not impact the biological properties of the medicinal product, and

(d) do not interfere with quality control tests.

Otherwise an adapted method has to be validated, as demonstrated here in terms of microbiological testing.

The requirement to test for $P$. acnes in our protocol requires the incubation of samples for 14 days, but depending on the study and its matrix, $P$. acnes may not belong to relevant microorganisms, thus an incubation period of 7 days may be sufficient in those cases. This again emphasizes the importance of a reasonable composition of the spectrum of tested microorganisms based on a preceding risk analysis.

The use of antibiotics within the culturing media of cellular products should be long enough to cover at least 3 population doublings of the microorganisms of interest but as short as possible, in order to limit unnecessary exposure of the recipient of cell products to antibiotics used for culturing the ATMP. In the present work the addition of antibiotics was limited to the first $8( \pm 1)$ days. The subsequent interim cell harvest, the following media ex- changes (Fig. 2), and the final harvest with resuspension of the cells in new media reduced the concentration of the remaining antibiotics to clinically negligible values.

When planning a method validation, one should always consider that procedural details like preanalytical issues (e.g., time frames), inoculation/testing volumes, etc. have to be strictly followed once the method is used as a validated test. Thus, possible practical obstacles at later time points - i.e., when the validated procedure has to be followed - have to be identified before planning the validation and have to be considered within the validation plan.

Based on the demonstrated example we emphasize that the success of clinical trials critically depends on the quality of the investigational medicinal products, not only in terms of comparability of data obtained from individuals subjected to the ATMP, but also in terms of feasibility of the study which may need to be stopped if concerns are raised on the safety of the investigational product. Thus, the choice of microorganisms for the validation of the microbiological test should always consider all conceivable scenarios and should not be reduced to minimal criteria defined in European Pharmacopoiea, wrongfully believing to thus save time and effort.

\section{Acknowledgments}

The study was part of the ADIPOA2 Trial (Clinical trial full name: A phase $2 b$ Study Evaluating the Efficacy of a Single Injection Autologous Adipose Derived Mesenchymal Stromal Cells in Patients with Knee Osteoarthritis) funded by Horizon 2020 (Grant agreement No. 643809).

We thank Ms. Kirsten Fischer and Dr. Thomas Dengler for technical assistance and plausibility proof of data obtained in the Institute of Transfusion Medicine and Immunology in Mannheim. 


\section{Statement of Ethics}

The study protocol was approved by the ethics committee of the University of Ulm. Subjects donating fat tissue gave informed consent.

\section{Disclosure Statement}

The authors have no conflicts of interest to declare.

\section{Author Contributions}

R.L. designed the study, evaluated the data, and wrote the manuscript. M.T.R., O.P., U.N., and H.S. contributed in designing the study and evaluating the data. P.H.Z. and W.F. gave individual medical and background information to the donors, were responsible for informed consent, performed liposuction, and contributed intellectually in designing the study.

\section{References}

1 Sensebé L, Gadelorge M, Fleury-Cappellesso S. Production of mesenchymal stromal/stem cells according to good manufacturing practices: a review. Stem Cell Res Ther. 2013 Jun; 4(3):66.

2 Galipeau J, Sensébé L. Mesenchymal Stromal Cells: Clinical Challenges and Therapeutic Opportunities. Cell Stem Cell. 2018 Jun;22(6): 824-33.

3 Haack-Sørensen M, Juhl M, Follin B, Harary Søndergaard R, Kirchhoff M, Kastrup J, et al. Development of large-scale manufacturing of adipose-derived stromal cells for clinical applications using bioreactors and human platelet lysate. Scand J Clin Lab Invest. 2018 Jul; 78(4):293-300.

4 Fekete N, Rojewski MT, Fürst D, Kreja L, Ignatius A, Dausend J, et al. GMP-compliant isolation and large-scale expansion of bone marrow-derived MSC. PLoS One. 2012;7(8): e43255.
5 Rojewski MT, Fekete N, Baila S, Nguyen K, Fürst D, Antwiler D, et al. GMP-compliant isolation and expansion of bone marrow-derived MSCs in the closed, automated device quantum cell expansion system. Cell Transplant. 2013;22(11):1981-2000.

6 Lovern D, Katzin B, Johnson K, Broadwell D, Miller E, Gates A, et al. Antimicrobial binding and growth kinetics in BacT/ALERT ${ }^{\circledR}$ FA Plus and BACTEC ${ }^{\circledR}$ Aerobic/F Plus blood culture media. Eur J Clin Microbiol Infect Dis. 2016 Dec;35(12):2033-6.

7 Flayhart D, Borek AP, Wakefield T, Dick J, Carroll KC. Comparison of BACTEC PLUS blood culture media to BacT/Alert FA blood culture media for detection of bacterial pathogens in samples containing therapeutic levels of antibiotics. J Clin Microbiol. 2007 Mar; 45(3):816-21.
8 Plantamura E, Huyghe G, Panterne B, Delesalle N, Thépot A, Reverdy ME, et al. Validation of the BacT/ALERT ${ }^{\circledR} 3 \mathrm{D}$ automated culture system for the detection of microbial contamination of epithelial cell culture medium. Cell Tissue Bank. 2012 Aug;13(3):453-9.

9 Skubis A, Gola J, Sikora B, Hybiak J, PaulSamojedny M, Mazurek U, et al. Impact of Antibiotics on the Proliferation and Differentiation of Human Adipose-Derived Mesenchymal Stem Cells. Int J Mol Sci. 2017 Nov; 18(12):ijms18122522.

10 Bourin P, Bunnell BA, Casteilla L, Dominici M, Katz AJ, March KL, et al. Stromal cells from the adipose tissue-derived stromal vascular fraction and culture expanded adipose tissue-derived stromal/stem cells: a joint statement of the International Federation for Adipose Therapeutics and Science (IFATS) and the International Society for Cellular Therapy (ISCT). Cytotherapy. 2013 Jun;15(6):641-8. 